Voix et Images

voixetimages

\title{
Se confier à la source
}

Paul Chamberland

Volume 23, numéro 2 (68), hiver 1998

La censure 1920-1960

URI : https://id.erudit.org/iderudit/201376ar

DOI : https://doi.org/10.7202/201376ar

Aller au sommaire du numéro

Éditeur(s)

Université du Québec à Montréal

ISSN

0318-9201 (imprimé)

1705-933X (numérique)

Découvrir la revue

Citer cet article

Chamberland, P. (1998). Se confier à la source. Voix et Images, 23(2), 406-409.

https://doi.org/10.7202/201376ar

Ce document est protégé par la loi sur le droit d'auteur. L'utilisation des services d'Érudit (y compris la reproduction) est assujettie à sa politique d'utilisation que vous pouvez consulter en ligne.

https://apropos.erudit.org/fr/usagers/politique-dutilisation/
Cet article est diffusé et préservé par Érudit.

Érudit est un consortium interuniversitaire sans but lucratif composé de l’Université de Montréal, l'Université Laval et l'Université du Québec à Montréal. Il a pour mission la promotion et la valorisation de la recherche. https://www.erudit.org/fr/ 


\section{Poésie}

\section{Se confier à la source}

\section{Paul Chamberland, Université du Québec à Montréal}

À ma connaissance, on n'a guère accordé l'attention qu'il aurait dû s'attirer au considérable phénomène éditorial qu'est la publication toute récente de Réveiller le rêve ${ }^{1}$ de Raôul Duguay. En consultant la liste des œuvres publiées, on constatera que, à l'exception de Kébèk à la porte (poèmes politiques: 1967-1993) ${ }^{2}$, paru en 1993, l'année 1981 ouvre un intervalle de silence long de quinze ans (je ne tiens pas compte de la discographie, qui, du reste, ne figure pas à la rubrique "du même auteur"). Que soit mis fin à un tel silence est déjà remarquable; la nature de l'objet publié l'est bien davantage et c'est pourquoi en donner une brève description permettra qu'on s'en fasse une idée. Réveiller le rêve forme le premier titre d'une rétrospective annoncée par tranches de décennies. En quatrième de couverture, on lit ces mots qui définissent bien le sens et la portée du projet: "Ce livre est le tome I de ma mémoire d'une autre réalité, celle qui m'a fait passer du livre lu par une élite intellectuelle au livre pour l'oreille, spectacle multimédia populaire." La seule réédition des premières œuvres poétiques, Ruts et Or le cycle du sang dure donc $^{3}$, depuis longtemps introuvables, justifie amplement l'entreprise. Mais on trouvera bien davantage. Notamment le long essai introductif (sections I à V) qui, par le biais d'un récit autobiographique retraçant les années d'apprentissage et avec les commentaires sur les deux premières œuvres (sections IX et X), propose une poétique soigneusement élaborée, susceptible d'éclairer l'œuvre de Duguay en ses commencements. Les sections VI, VII et VIII reprennent des écrits d'époque: conférences, 
comptes rendus et critiques (ces dernières, toutes parues dans la revue Parti pris). Enfin, la dernière section (XI) rassemble articles ou comptes rendus qui témoignent de la réception accordée aux premières ouvres ou aux spectacles donnés par le poète au cours des années soixante. L'ouvrage, on a plaisir à le tenir dans les mains et à le palper: la facture éditoriale de grande qualité distingue l'excellent travail de l'éditeur VictorLévy Beaulieu. De grand format, le livre donne aux poèmes un large espace où respirer.

Le long essai qui forme l'introduction au livre passionnera tous ceux qui apprécient la poésie et l'art de Raôul Duguay. Deux trames s'y entrelacent étroitement, celle de l'autobiographie et celle de la méditation sur la poésie ou sur l'art. La première, en donnant des circonstances à l'autre, favorise la compréhension de la poétique de Duguay dans son devenir même; ainsi voit-on de manière précise les diverses composantes de son art prendre forme, se développer et s'articuler entre elles pour produire ce style unique dans la poésie québécoise contemporaine. De l'Abitibi natale jusqu'aux spectaculaires interventions d'" art total" ou "global" de l'étudiant en philosophie à l'Université de Montréal au cours des années soixante, l'enfant, l'adolescent, le jeune homme nous sont successivement dévoilés en un récit émouvant qui fait alterner épreuves d'un réel rugueux et fulgurants éblouissements générateurs de poésie. Particulièrement révélateur le témoignage de la précoce "confrontation" entre l'amour et la religion qui se noue en cette "première contradiction: le sexe sacré" (p. 30) puisqu'il fournit la clé de l'axe majeur de la poésie de Duguay: une érotique spirituelle/cosmique conjuguant l'adoration, la rébellion ("la poésie n'est pas que belle, elle est rebelle", p. 78) et la turbulente générosité du vivre.

"La source sourd de l'Abitibi." (p. 21) Tout vient de la source. Entendez que l'imaginaire de la source est assez fort et fécond pour soutenir et même précipiter la confrontation avec le réel, et pousser l'enfant de Val-d'Or à l'irrésistible désir de réconcilier les parts opposées du rêve et de la réalité. "Le dur désir de durer" (p. 67), repris d'Éluard, vaut à cet égard comme formule clé et l'auteur, dans une page forte, en fait valoir toute l'alchimie secrète. La source est autant endogène que forestière: surgie du cri, c'est la "source rouge" (p. 18) de l'appétit de vivre et d'aller libre au-devant de l'accomplissement promis par Éros. L'acte qui rend (à) l'immédiat et n'est tel que d'être commencement sans cesse réitéré donne à l'écriture son impulsion et sa destination: "J'écris des mots dans l'eau de la source." (p. 23)

Le métaphore fluviale va traverser et ponctuer les trois premières sections de la poétique autobiographique: la source (I), le ruisseau (II), la rivière (III). Flux et rythme, terre et chair, fusionnés dans l'échappée du chant, qui est l'oiseau dont la trajectoire n'a d'autres limites que celles de l'univers. La poétique de Duguay peut être tenue pour une véritable poiétique dans la mesure où elle dégage et conjoint toutes les "sources" de l'acte créateur. Si elle a pu déconcerter, c'est sans aucun doute parce qu'elle est, d'un seul tenant, un processus psychique et spirituel tout orienté par la quête de l'illumination 
et une "physique" enracinée dans la chair de la phonè, la matière du souffle signifiant. L'élément médiateur, proprement énergétique, est la force vitale de l'Éros. On ne s'étonnera pas d'apprendre qu'"[...] aussi loin que je me souvienne, la source de ma poésie s'est toujours abreuvée à ma soif d'une femme" (p. 61). Ruts, nous révèle l'auteur, est le fruit d'une alchimie érotique qui s'élabore depuis "le désir [...] de fusionner le sexe, le sentiment et le sacré" (p. 62). Cosmique, psychique et sexuelle, la source est bien le paradigme majeur de la poïétique de Duguay:

\begin{abstract}
La source sourd du rocher. L'eau de source n'est pas pressée de couler. Je pose ma tête contre le rocher. L'oreille collée sur la paroi comme un stéthoscope, j'écoute. J'entends battre le cœur de la Terre. J'entends sourdre, des entrailles du royaume minéral, la source même de la source. [...] J'entends monter son chant jusque dans mon oreille [...]. Et son cycle à jamais perdure: si la source descend du ciel, c'est pour y remonter, avec l'aide du soleil. Ainsi le soleil dans le ciel et l'eau de la terre bénissent sans cesse l'existence de la vie. C'est ce couple cosmique, assoiffé de luimême, qui donne un sens à tout ce qui vit sur Terre. (p. 35)
\end{abstract}

En maints passages, Duguay donne de précises et de précieuses indications sur cette composante majeure de sa poétique: la "musique" inscrite dans la chair du son. Précoce apparaît la "tentative" de "former un nouveau code poétique" qui se veut "retour à la source même du langage : la phonétique, la phonologie et la phonématique" (p. 64). D'où l'étude des "formants ou fréquences vibratoires" (p. 64). Ainsi est-ce dès Ruts et Or le cycle du sang dure donc que la "musique" "envahit" son écriture, comme le manifestera avec évidence l'œuvre ultérieure, tant celle du poète que du chanteur. Le passage suivant me paraît bien résumer la poétique de Duguay: "Quand je crée le poème, je rêve éveillé. Une partie de la réalité du poème puise sa source dans le réel concret. L'autre partie est littéralement sublimée, idéalisée, inventée de toutes pièces par la perception instantanée des rapports nouveaux qui émanent des mots, images ou sonorités qui se présentent à la raison et à l'intuition." (p. 66)

De nombreux passages de l'introduction suscitent l'intérêt quant à la part déterminante, pour la genèse de l'œuvre, de la musique contemporaine et du jazz (dont l'auteur reconnaît "l'impact réel sur [sa] perception du son et du rythme dans [sa] poésie", p. 83) et, bien entendu de l'œuvre de certains poètes, notamment celle du Saint-Denys Garneau de Regards et jeux dans l'espace ${ }^{4}$ et celle de Jean Narrache.

Enfin un mot sur les deux premiers livres de Duguay. Une fois dissipé l'effet tabou qui ont marqué à l'époque leur réception, ils ont remarquablement bien vieilli. La facture rythmique et le réseau d'images y conservent toute leur fraîcheur. Ces poèmes sont formés selon une syntaxe poétique à la fois vigoureuse et rigoureuse. Les effets de ruptures (la pulsation syncopée du jazz) et l'appui rythmique des allitérations font la puissance de ce généreux lyrisme érotique.

$\mathrm{Au}$ moment où j'écris ces lignes vient de paraitre un nouveau livre de poèmes de Raôul Duguay, $N u$ tout $n u$, Le rêveur réveillé, aux Éditions Trois-Pistoles. À suivre... 
1. Raôul Duguay, Réveiller le rêve suivi de Ruts et de Or le cycle du sang dure donc, Trois-Pistoles, Éditions Trois-Pistoles, coll. "Classiques *, 1996, $369 \mathrm{p}$.

2. Id, Kébèk à la porte (poèmes politiques: 1967-1993), préface de Victor-Lévy Beaulieu, Montréal, Éditions Stanké, coll. 410/10 actuel $n, 1993,223 \mathrm{p}$

3. Id., Ruts, Montréal, Éditions Estérel, 1966 et Éditions de l'Aurore, coll. * Lecture en vélicipède., 1974; Or le cycle du sang dure donc, Montréal, Éditions Estérel, coll. "Quoi ", 1967 et Éditions de l'Aurore, coll. * Lecture en vélocipède 1975.

4. Saint-Denys Garneau, Regards et jeux dans l'espace, Euvres, texte établi, annoté et présenté par Jacques Brault et Benoît Lacroix, Montréal, Les Presses de l'Université de Montréal, 1971, $1320 \mathrm{p}$ 